\title{
Use of wearable devices in medicine and in paramedical education and the need for training of medical data scientists
}

\author{
Hidetsugu Kohzaki ${ }^{*} \uparrow$, Yoichi Ishida ${ }^{\ddagger}$, Yoichi Fujita ${ }^{\S}$
}

\begin{abstract}
Wearable devices have been developed by various companies globally. In this new business, devices that measure, collect, and analyze vital signs are sold as packages. Wearable devices are particularly beginning to be utilized in medical care. Here, we clarify the advances made by medical institutions and the convenience of using the information and communications technology made available by wearable devices. We then discuss the handling of data collected from these devices and the problems faced by human resources development to master these data.
\end{abstract}

Keywords: Education, Medical Institution, Medical profession, Wearable device, Medical data scientists

\section{Introduction}

Utilization of ICT (Information and Communications Technology)—for example electronic medical records-is being progressively shared throughout the medical field, starting with the bigger institutions. Not only personal information such as a patient's medical history, but also X-rays, CT scans, MRI images, and even genetic information are sometimes handled. Security guidelines have been established for medical institutions [1], and there are certifications for medical information-handling professions such as Network Administrator, Healthcare Information Technologist (Japan Association for

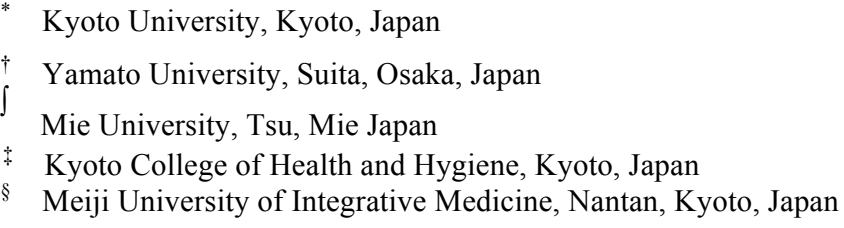


Medical Informatics) [2], and Health Information Manager (Japan Hospital Association) [3]. In reality, however, because such certification alone is not enough to get hired and the salaries for such jobs in Japan are low, other healthcare professionals with national licenses often obtain certification to fill the positions concurrently with their own jobs. Although the development of data scientist training has been gaining momentum in recent years [4], it is still in the early stages. In the healthcare field, as our population ages, the industrial, government, and academic sectors have been taking the initiative to provide medical care to remote locations, amend regulations to widen the scope of practice for registered nurses, and develop strategies to provide faster and more convenient medical care [5].

Wearable devices are being developed by various companies [6]. Packaged applications that can monitor, collect, and analyze a patient's vital signs are being marketed, and a new healthcare business has emerged. However, many issues remain. For example, it is uncertain who should collect the data, where and for how many years they should be kept, and how they should be applied to, for example, preventive medicine. Our aim here was to examine the utilization of ICT by medical institutions, the usability of wearable devices, how the collected data should be handled, how to compensate for the shortage of qualified human resources for handling such data, and how this personal medical information can be applied to healthcare services.

\section{Wearable device}

2.1 What is a wearable device?

In recent years, smart devices (e.g. smart phones and tablets) and wearable devices have become prevalent in the ICT market $[7,8]$. Their use among general consumers has started to become widespread, and their use in the medical field is being explored. A wearable device is an electronic device designed to be worn on the human body (e.g. on an arm or the head). The concept of moving around with a computer attached to the body has been around for quite a while. A version of the idea can be seen in science fiction drama from around the 1960s, and 20 to 30 have passed since the first 
application at a practical level. Computers back then were huge, and the idea of carrying around a small smart device was almost a fantasy. However, cellphones started to incorporate more functionality and eventually evolved into smartphones. Nowadays, it is the norm for people to constantly carry around a device equipped with the same functionality and performance as previous-generation PCs. Moreover, most of the expected functions of wearable devices can now be accomplished by using a smartphone. For this perspective, today's wearable device is no longer a "wearable high-performance computer:" it is considered more of "a peripheral device that complements the functions that the smartphone alone cannot achieve".

Typical examples are wearable devices that incorporate healthcare functionality, such as Fitbit, Fuelband, Misfit Shine, and Jawbone Up, which have garnered a lot of attention for their fashionable designs. These devices not only have pedometer functionality with an acceleration sensor but also in some cases allow GPS tracking and pulse-rate monitoring. While the user is exercising (e.g. running), the device is dedicated to recording the data. Then the data are uploaded to a smartphone or PC for aggregation and analysis. Cloud services are also available: users can upload their data to the cloud to view or compare them to chronological training data later at any time. These devices are designed to be used in conjunction with other devices or with a cloud; they are therefore very different from the conventional mono-function pedometer. For example, the "+Nike" option for iPod complements the functionality that an iPod does not have. Moreover, users have the advantage of being able to use wearable devices alone, without the help of other smart devices. Other available applications include a device attached over the heart to a T-shirt, or contact lenses that measure the sugar concentration in tears. This area has been rapidly evolving and progressing.

\subsection{Regional health information networks}

Today, regional healthcare systems in Japan are collaborating nationwide. Under the leadership of core hospitals and the medical association, collaboration frameworks are being established in many regions. Local clinics and (in some cases) pharmacies are participating in the networks. 
Such networking is expected to promote a collaborative medical treatment system that allows multiple medical institutes to share or consult on medical information and to refer patients back and forth. It is also expected to help improve home healthcare services by sharing patients' "nursing records."

Successful examples include Net4U (Tsuruoka City, Yamagata Prefecture), Kakogawa Community Health and Medical Care Information System (Hyogo Prefecture), and the Ajisai Network (Nagasaki Prefecture)[9].

After the success of "99 Saga Net" [10], which is an information system used by Saga Prefecture's emergency medical service, such systems are becoming widespread in line with local needs.

\subsection{Current ICT skill levels of healthcare professionals}

Being educators involved in ICT education at a medical trade school, we noticed that most new students were well acquainted with how to use portable information devices such as cellphones and smartphones; however, even those who had supposedly studied ICT as part of their compulsory schooling (i.e. those who had studied "Information" in junior high school) seemed to have very little experience with personal computers for creating documents, using spreadsheets, and giving presentations using presentation software [11]. In the case of healthcare providers currently engaged in the job, it seemed that the older they were, the less they knew. Their knowledge level depended on their degree of personal interest and on the training provided by each medical institute. Therefore, staff levels of ICT skill should be borne in mind when points 2.1 and 2.2 above are examined from the perspective of the utilization of medical information.

\subsection{ICT literacy of healthcare professionals}

We are engaged in training nurses, medical technologists, and physical therapists. In terms of ICT literacy skills, our students have not yet reached a level high enough to perform network management, data management, or data analysis $[12,13,14]$, but we have finally brought them to a level where they can take a class using an iPhone/iPad2/Tablet, gather a variety of types of 
information, and discuss actual data obtained in real time from medical personnel [15]. Still, we have a long way to go. Another concern is that the teaching skill levels of the instructors are not high enough [12]. It may take some time, but progress should be made by a society as a whole.

\section{The need to include portable information devices in the education field}

In March 2010, Microsoft launched HealthVault Community Connect, which is software that enables the viewing and recording of patients' medical data. Recently, various portable information devices running Android or iOS operating systems have begun to appear in the healthcare field. They allow immediate access to, and sharing of, medical information between healthcare providers and patients; this is also helpful when obtaining informed consent from patients.

A survey of medical personnel has shown the usefulness of the iPad [16]. It is even more useful when used with a cloud system suited to business needs such as outpatient treatment, surgery/testing, hospital ward management, or medical accounting.

An abundance of applications are now available: more than 4000 medical-related applications have been developed. The software is starting to be applied to actual medical scenarios for the purpose of smooth running of medical treatment teams, better communication between healthcare teams and patients, provision of healthcare at a distance, and the interpretation of X-ray films or electrocardiographic or radiographic images. The benefit of mobile information devices is that they allow healthcare providers to retrieve the necessary information from anywhere, anytime when needed.

In the past, healthcare providers simply had to process paper-based documents such as medical records, like an assembly line. However, as ICT utilization has progressed in the medical field, demand has increased for competent personnel who are able to properly use Healthcare Information Systems, which are the backbone of medical management, and to handle electronic medical records. An understanding of the cloud system has also become necessary. 
The cost of printing images, such as images of pathology tissue specimens, was a problem in the past. Today, high-resolution images processed on the computer are in high demand in the field of pathology for histological examination of stained cells or tissues, as well as in the area of electrocardiography. Even free software is distributed for use in the fields of anatomy, electrocardiography, and ultrasonography.

For these reasons, we decided to develop an educational curriculum on how to use portable information devices. It aims to achieve the following: (1) in team medical care using portable information devices, familiarity with how to communicate with healthcare professionals (especially with a doctor making a diagnosis) and the process of obtaining informed consent; (2) ability to download study materials and class materials from a server by using a portable information device without constraints of time and place, so that students can independently review or prepare for a class; and (3) familiarity with various types of software and applications.

\section{Educational curriculum on assumed use of portable information devices in the medical field}

We developed an educational curriculum on the assumed use of portable information devices in the medical field (Table 1). This curriculum is designed for those who have completed Medical Information Management Practice I and II.

The basic operation of portable information devices does not differ largely from the operation of personal computers. We consider that the focus of education should be on understanding the concept of cloud computing, mastering the use of the software commonly used by doctors, and improving presentation skills by using portable information devices in various settings (e.g. where informed consent needs to be obtained). Presentation training classes are included in the curriculum, because in the medical field there is a need to give presentations regardless of time and place. 
Table 1 Example of our educational curriculum on the use of portable information devices

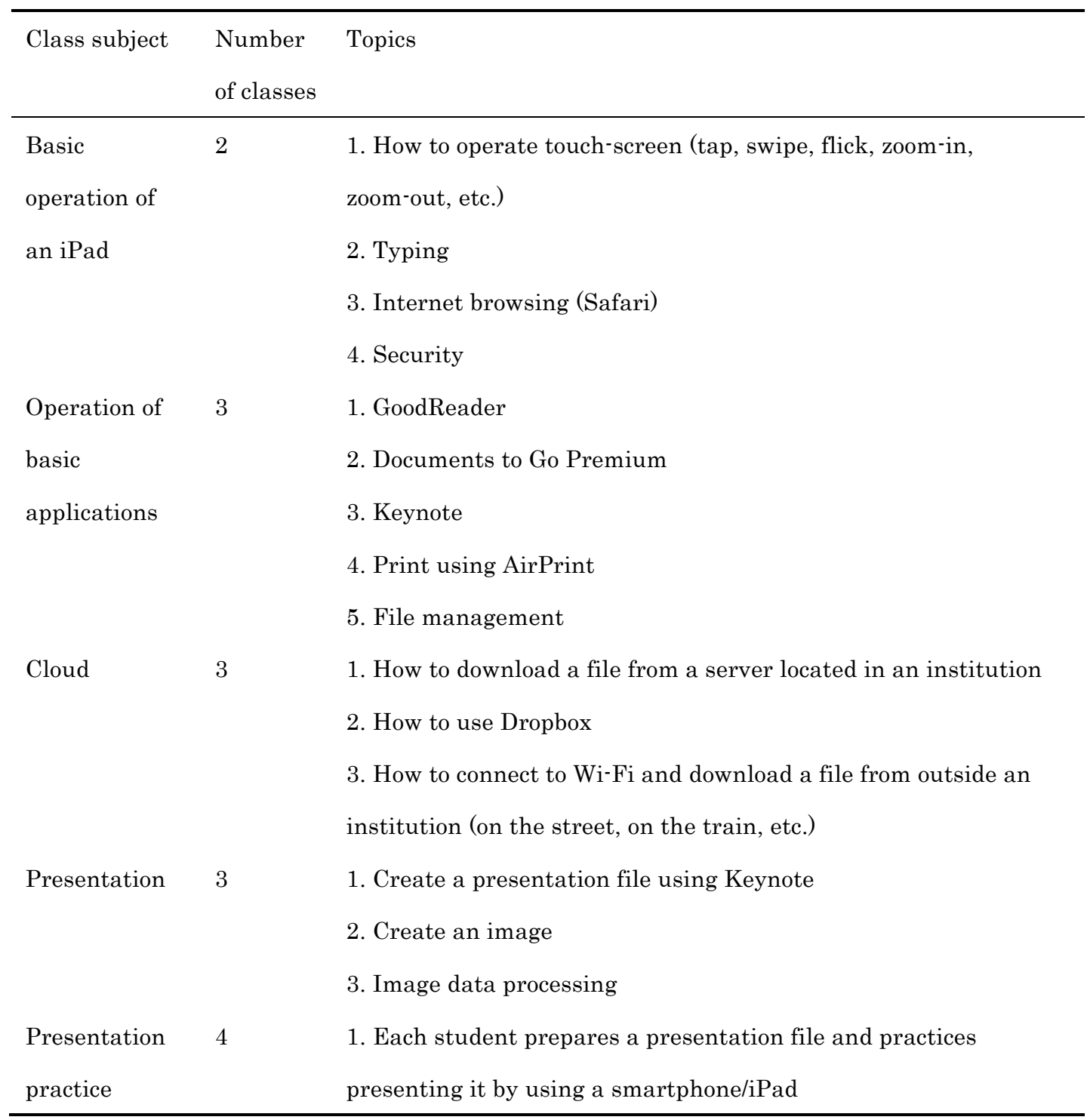

Also, for example, Digital Globe has recently developed a cloud-based electronic medical record system called Open Dolphin. Using portable information devices makes it possible for healthcare providers to easily share medical information such as electrocardiogram and echocardiogram results. Use of 3D images is also possible in the fields of anatomy and physiology. Often, free applications are of very high quality-enough to be used as readily available software in the medical field. In this respect, a standard for the adoption of applications should be developed (e.g. GMP/QMS (JIS Q 13485; 
alternatively a quality-management system is an option). Therefore, information related to these topics should also be taught.

The curriculum that we developed as part of this study devotes considerable time to learning how to use applications that utilize the unique characteristics of portable information devices (especially applications and cloud systems used in the medical field) and how to prepare a presentation in order to communicate with other healthcare providers or obtain informed consent from patients.

After students completed the curriculum, we conducted a survey and received the following typical comments to free-answer questions: "The X-ray, electrocardiogram, and echocardiogram images are very easy to read, and it should make it easier for us to explain things to the doctors;" "Exchange of data is easy, and data entry is done on the spot, just as if I am just taking notes. It's convenient;" "Now I am used to the cloud system. I won't have any problems with it when I get a job;" "The image quality of the cells and stained cells in the teaching material was very clear and easy to understand;" and "I can zoom in and out quickly. It helps me see better."

\section{Results}

Starting from the 2012 academic year, we have implemented an information science class (ICT-use training) with the aim of teaching students how to use portable information devices as paramedical staff in the medical field. Previously, our students had no, or very little, opportunity to make presentations, but they are now given a chance to demonstrate their presentation skills (approximately once each semester) by using a portable information device in front of fellow students, teachers, and healthcare providers from outside (around 120 people). The students don't appear to be nervous while giving their presentations, and the presentation contents are good and clear. Their skills have improved, and now they are able to handle question-and-answer sessions properly.

Another effect of offering the class on the use of portable information devices is that the students voluntarily start to search for information-not only on topics related to medical technologists but also, for example, about the hospital 
where they will receive practical training or where they wish to work. Also, the students start to ask the teachers more technical questions and seem to be more interested in the difference between medical technologists and other medical providers, as well as in the specific job roles of medical technologists.

Many students have begun to use portable information devices to learn how to perform the tests that medical technologists perform; to explain data on simulated practices; and to discuss issues with each other. They have more chances to practice their presentation skills and to conduct peer evaluations; these exercises also serve as good practice for obtaining informed consent. In the past, students had limited experience in making presentations and attended classes in a passive manner. It was also typical for students to ask for an immediate answer from a teacher without thinking or investigating for themselves whenever a question popped up. However, since portable information devices were introduced, they have learned to express their own opinions clearly to an outside party and to use the devices to find the answers to their questions voluntarily and independently. Although all of these changes did not necessarily result from education using portable information devices, the changes in the students' attitudes towards learning were likely the fruits of the introduction of this program.

In this study, we developed a curriculum to train students, while they are still at school, up to a level at which they are able to freely use a portable information device and to acquire presentation skills good enough to obtain informed consent.

With ICT utilization rapidly growing, it is becoming increasingly necessary for healthcare providers to gain knowledge of information science. Some medical institutions have already adopted the use of portable information devices in their hospital information systems, because it is critical for them to have an accurate awareness of the constant changes in patient information (such as vital signs or the status of a surgical procedure). Considering the increased demand arising from the medical community, the curriculum in this program can be used to retrain medical staff who has already been working in the field for quite a while. 
The 2009 Information and Communications White Paper [17] shows that the utilization of telecommunications in the Medical and Welfare area in Japan is significantly lower than in other countries advanced in ICT, although it has shown some sign of improvement in recent years. In the United States, a service that uses telecommunications technology has started to be put to practical use. There, the comprehensive medical information that healthcare providers handle every day (such as medical records, medication records, and information on daily physical condition) is centrally managed through IT in the form of EHRs (electronic health records) and PHR (personal health records), with the aim of establishing a network within medical institutions and among those treating patients. Therefore, training programs on the use of such devices seem to be more common in the US.

In contrast, Japan is yet to see widespread implementation of even electronic medical records. Ikeda [18] pointed out that "iPads are being introduced widely in medical education at Stanford University School of Medicine, and this is anticipated to increase in the future." In fact, according to the 2012 Information and Communications White Paper [19], the use of smartphones is globally widespread. Tablets, in particular, are actively used as electronic textbooks.

The white paper [19] also gives examples of service application in the medical, welfare, and healthcare service fields in Japan. This includes a system whereby patients are able to see their primary care physicians and get medical advice directly via a terminal screen. Globally, in the education field, including in medical education, the so-called three ICT items of education (electronic blackboard, educational tablet, and electronic textbook) are being introduced. Electronic blackboards are the most widespread in England. Russia, Middle Eastern countries, and African nations are increasingly giving preference to investing in electronic blackboards instead of teacher training. Also, in Korea, introduction of the use of electronic textbooks for instruction in all elementary and junior high schools was completed in 2012. The plan also included the distribution of one educational tablet per student in 2013. Similar initiatives are under way in Singapore and Thailand. In Takeo City, in Saga Prefecture, Japan, it was decided that tablets would be distributed to all elementary and 
junior high school students in the 2014 academic year.

As educational tablets designed to read electronic textbooks, Intel Corporation is marketing "Classmate PC" worldwide; Apple iPads are also leading candidates.

We plan to continuously follow up on this study and evaluate the effectiveness of our educational curriculum.

\section{Conclusions}

Table 2 Beginners-level training offered by the Data Scientist Society

\begin{tabular}{|l|l|l|}
\hline 1st class & Basic data analysis & $9: 30-17: 30$ \\
\hline 2nd class & Basic logical thinking & $9: 30-17: 30$ \\
\hline 3rd class & Basic marketing & $9: 30-17: 30$ \\
\hline 4 th class & Basic marketing research & $9: 30-17: 30$ \\
\hline $\begin{array}{l}\text { 5th class } \\
(2 \text { days })\end{array}$ & $\begin{array}{l}\text { [Crash course] Introduction to data } \\
\text { analysis/Basic data analysis }\end{array}$ & $9: 30-17: 30$ \\
\hline
\end{tabular}

As explained above, to catch up with the rapidly developments in ICT healthcare equipment, there is a need to develop educational programs, namely lectures for students at school and continuing education for healthcare professionals who have already left medical school or medical trade school.

In fact, we developed an educational curriculum on the assumed use of portable information devices in the medical field (Table 1). As described above, students have improved not only their ICT and presentation skills but also communication and willingness to learn. Theses results showed the unexpected educational effects.

The Data Scientist Society states that a data scientist should possess "business skills," "data scientist skills," and "data engineering skills" [20]. The Society offers training courses (Tables 2,3). However, these courses are not free; course participants can expect to pay. Also the courses seem a little hard for students who do not have some level of ICT literacy and knowledge of finance and statistics in these short periods. It seems to be difficult to fix the 
knowledge for a long time.

Recently, Statistics Bureau, Ministry of Internal Affairs and Communications, Japan has started Data Science online courses, "Data science Introduction to the working people" using the mooc for free [21]. But this is not a specialized to medical fields unfortunately.

Table 3 Intermediate-level training offered by the Data Scientist Society

\begin{tabular}{|l|l|l|}
\hline 1st class & Easy! Basic cluster analysis & $9: 30-17: 30$ \\
\hline 2nd class & $\begin{array}{l}\text { Clear! Cluster analysis of data, } \\
\text { including big data }\end{array}$ & $9: 30-17: 30$ \\
\hline
\end{tabular}

Table 4 Education on ICT medical devices and wearable devices

\begin{tabular}{|l|l|}
\hline Lecture & Practice \\
\hline equipment & $\begin{array}{l}\text { Instruction on how to use various medical healthcare } \\
\text { equipment }\end{array}$ \\
\hline $\begin{array}{l}\text { How to connect medical healthcare } \\
\text { equipment to a portable device }\end{array}$ & $\begin{array}{l}\text { Practical training in connecting the medical } \\
\text { healthcare equipment to a portable device }\end{array}$ \\
\hline $\begin{array}{l}\text { Overview of cloud computing and } \\
\text { databases }\end{array}$ & Development of a cloud system and database \\
\hline $\begin{array}{l}\text { Security when handling medical data } \\
\text { in a cloud }\end{array}$ & Security \\
\hline Application to personalized medicine & Diagnostic case study using vital signs, X-ray, CT, \\
\hline How to analyze big data (R language, \\
Python, SAS, Stata and so on)
\end{tabular}

Note: Each lecture corresponds to the practice in the right column.

In order to solve the problems in Table2 and 3, Table 4 is our own training plan designed especially for the medical field. It is an advanced class of the Information Science taught in junior high and high schools. It covers medical healthcare devices and portable devices used by healthcare professionals. It also deals with topics that are primarily for medical radiation technologists, 
such as X-ray, CT, MRI, 3D softs. Learning these topics will be beneficial for students studying to be nurses, medical technologists, or physical therapists, as it enhances understanding of the different medical professions working as a medical team. We are considering executing this plan at medical universities and medical trade schools and evaluating progress in class and in continuing education. The problem, however, is that education takes time. Also, every medical institution has its own pace when it comes to introducing new medical equipment, and this means that there may be no opportunity to use newly acquired skills or knowledge. Therefore, when we move ahead with this plan, detailed information such as the local condition and situation of the medical institution should be taken into account. Having said that, the $\mathrm{R}$ language and others in the curriculum is the basis for data analysis, and at the present time mastering this language alone may be enough to get hired. Efforts should therefore be made to make time to study $\mathrm{R}$ and others.

So, what has to be done to enable students and medical professionals to catch up with the developing medical technology? There are limits to what we can expect from medical schools or medical trade schools. Therefore, besides attending lectures, students need to commit to improving their skills by using their own initiative. Also, they need to acquire a good educational foundation and ICT literacy that allows them to adapt to any changes in society.

We propose to train students to become medical data scientists. Medical data scientists comprehensively analyze various important medical data (medical big data), such as patients' vital signs, constitutions, lifestyles, medical records, electronic medical records, medical images, and genetic information. They help to improve the early detection and prevention of diseases and contribute effectively to personal health. We previously proposed to create and train

"Genome Consultants" or "Genome Inspectors" (these are tentative names), whose main purpose was to handle genetic information [22]. However, we now consider that the role of Genome Consultant can be integrated into that of Medical Data Scientist, and once again we propose to found and train Medical Data Scientists. We believe that our curriculum and that of the Data Scientist Society (Tables 2 to 4 ) can be used for this training. 
Recently, the ICT is utilized in various fields. Data distribution amount continue to increase year by year. The importance of security is increasing [23]. Although medical institutions security guidelines have been established, only small people are responsible for the actual medical information. From the viewpoint of a supplement of ICT and human resources shortage responsible for it of medical institutions, we propose educational trainings in the medical institution (Table.4). Students have started to understand the importance of security and to improve their problem solving skills including computer viruses, security holes of medical softs.

Overseas, mobile devices are widely used in medical education. In Japan, too, various kinds of software are being distributed. It is time to systematically develop programs to train healthcare professionals and also to develop continuing education programs for those who have already graduated from medical school or medical trade school.

\section{Acknowledgement}

We thank Dr. Yuichi Kogure (Aomori Public University) for helpful discussion. This work was partially supported by the Memorial Fund of the

$44^{\text {th }}$ Annual Meeting of the Japan Society for Clinical Laboratory Automation. H.K. was supported by my crowdfunding operated by Readyfor and the investors.

\section{References}

[1] Ministry of Health, Labor and Welfare. "Guidelines for safe management of medical information systems, edition 4.2,"

[2] Healthcare Information Technologist Certified by Japan Association for Medical Informatics (JAMI); http://www.jami.jp/jadite/new/doc/pdf/090522HealthITOverview.pdf

[3] Japan Society of Health Information Manager; http://www. jhim. jp/

[4] H. Kohzaki, "The need and the education of data scientist training," Computer \& Education, vol.38, 2015, pp.110-111.

[5] Ministry of International Trade and Industry, "It is in earnest efforts to health care business 
creation in the regions -To strengthen public-private partnerships, boost - the creation of the health care business in the regions-"; http://www.meti.go.jp/press/2014/09/20140901007/2014090 1007.html

[6] AW, Bates and AA, Gawande, "Improving Safety with Information Technology, " The New England Journal of Medicine, vol. 348, 2003, pp.2526-2534.

[7] AE. Hauser, D. Demner-Fushman, JL. Jacobs, SM, Humphery, C. Ford and CR. Thoma, "Using Wireless Handheld Computers to Seek Information ay the Point of Care: An Evaluation by Clinicians," Journal of the American Medical Informatics Association, vol. 14 , no. 6,2007 , pp.807-815.

[8] KA. Galt, "Personal Digital Assistant-based Drug Information Sources: Potential to Improve Medication Safety," Journal of Med Libray Association, vol. 93, no. 2, 2005, 229-236.

[9] "Basic plan of regional medical information network maintenance in Yamagata Prefecture"; https://www.pref.yamagata.jp/ou/kenkofukushi/090013/nwplan/nwplan.pdf.

[10] Saga medical institution information and emergency medical information system, "99 Saga net"; http://www.qq.pref.saga.jp

[11] Declines for safe management of medical information systems;

http://www. mh1w. go. jp/file/06-Seisaku jouhou-12600000. . . /000005334

1. pdf

[12] H. Kohzaki, "A Proposal for Information Science Education for Paramedics/Medical

Technologist Training in Japan," Journal of Educational Research and Reviews, vol.

1, no.3, 2013, pp.34-41.

[13] H. Kohzaki, and R. Sugawara, "Proposals and problems of ICT literacy education in medical technologists training," Computer \& Education, vol. 33, 2012, pp.104-105.

[14] H. Kohzaki, "Medical genetics education up to high school with genetic and ICT literacy," Journal of Chromosome and Genes Analysis, vol. 32, no. 1, 2014, pp.30-35.

[15] H. Kohzaki, Y. Ishida and Y. Fujita, and R. Sugawara, "Development of education programs and the need for mobile information communication terminal use education in medical technologists training,” Journal of Career Design Studies, vol. 9, 2013, pp.201209.

[16] H. Kohzaki and R. Sugawara, "Assurance of Quality of Paramedics Training Institutions-Focus on Academic Abilities of Teachers and Students-, " Journal of the Japan Association for Development Education, vol. 9, no. 1, 2014, pp.98-103.

[17] Ministry of Internal Affairs and Information and Communications White Paper 2009 fiscal year edition; http://www.soumu.go.jp/johotsusintokei/whitepaper/ja/h21/ 
[18] T. Ikeda, "Problems and future prospects of the medical applications of the portable information terminals," "Mobile Health 2010", Symposium "Subcommittee on medical applications of mobile communication terminal in Japan Association of Applied IT Healthcare.

[19] Ministry of Internal Affairs and Information and Communications White Paper 2012 fiscal year edition;

http://www.soumu.go.jp/johotsusintokei/whitepaper/ja/h24/html/nc122400.html.

[20] The Japan Data Scientist Society, "The mission, skill set, definition and skill level of Data scientists";

http://prtimes. jp/main/html/rd/p/000000005. 000007312.html

[21] Statistics Bureau, Ministry of Internal Affairs and Communications, Data

Science online courses, "Data science Introduction to the working people"; http://gacco.org/stat-japan/

[22] H. Kohzaki, "A proposal for clinical genetics (genetics in medicine) education for medical technologists and other health professionals in Japan.” Frontiers in Public Health, section Public Health Education and Promotion, "Research Topic", 2, Article 128, 2014, pp. $1-5$.

[23] H. Kohzaki and J. Yamadera, "The need for hackathon in medical institutions." Journal of the JPCATS, vol. 11, no. 1, in press. 